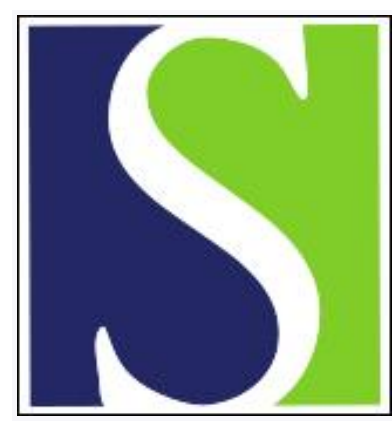

Scand J Work Environ Health 2000;26(2):169-177

https://doi.org/10.5271/sjweh.527

Issue date: Apr 2000

\title{
Unemployment and health care utilization
}

by Kraut A, Mustard C, Walld R, Tate $R$

The following articles refer to this text: 2003;29(1):15-21;

2007;33(1):29-36

Key terms: ambulatory care; employment; hospitalization; mental health

This article in PubMed: www.ncbi.nlm.nih.gov/pubmed/10817383

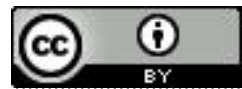




\title{
Unemployment and health care utilization
}

\author{
by Allen Kraut, MD, ${ }^{1,2}$ Cam Mustard, $S c D, 2,3,4,5,6$ Randy Walld, BSc, ${ }^{2,7}$ Robert Tate, PhD, 2,5
}

\begin{abstract}
Kraut A, Mustard C, Walld R, Tate R. Unemployment and health care utilization. Scand J Work Environ Health $2000 ; 26(2): 170-177$.

Objectives This study attempted to determine whether prior use of health services predicts a subsequent risk of unemployment and also to describe the acute effects of exposure to unemployment on the use of health care services.

Material and methods The 1986 census records were linked with comprehensive health care information for the period 1983-1989 for over 44629 randomly selected residents of Manitoba, Canada. All cause and cause-specific rates of hospital admission and ambulatory physician contacts were compared between 1498 unemployed and 18272 employed persons across 4 consecutive time periods related to the onset of unemployment.

Results The adjusted rates of hospital admission and physician contacts were higher among the unemployed across all 4 periods. When persons with a history of mental health treatment were excluded, health care use in the period prior to the onset of unemployment was equivalent among the employed and unemployed. When a history of mental health treatment was controlled for, all-cause and cause-specific health care use was elevated among the unemployed during the unemployment spell.

Conclusions Unemployed persons had increased hospitalization rates before their current spell of unemployment. Much of this difference was due to the subgroup with prior mental health treatment. For persons without prior mental health care, hospitalization increased after a period of unemployment.
\end{abstract}

Key terms ambulatory care, employment, hospitalization, mental health.

Both cross-sectionally and prospectively, unemployment has been found to be associated consistently with health status deficits across a broad range of health measures, including individual biological and behavioral responses, self-reported or objectively measured health and functional status, and mortality $(1-10)$. This relationship between unemployment and health may potentially be accounted for by the following 2 major competing explanations: (i) causation, where unemployment precipitates a decline in health, perhaps through the combination of effects arising from loss of income (11), increases unhealthy life-styles (12), loss of self-esteem (13), and psychological stress $(2,14)$ and, in some settings, reduces access to medical care; and (ii) selection, where a person's health status, gender, nationality, previous exposures to unemployment, or other personal characteristics simultaneously place them at higher risk for both unemployment and poor health $(7,8,15,16)$.

In prospective studies, several methodological issues have limited efforts to estimate the relative contribution of each of the competing explanations in accounting for the observed relationships. Efforts to estimate the direct impact of unemployment on health have been limited by several factors, including variations across studies in the definition of "exposure" to unemployment and whether and how studies are adjusted for potential confounding. Similarly, investigating the hypothesis that the association can be explained primarily by the selection of

1 Department of Internal Medicine, University of Manitoba, Winnipeg, Canada.

2 Department of Community Health Sciences, University of Manitoba, Winnipeg, Canada.

3 Population Health Program, Canadian Institute for Advanced Research, Toronto, Canada.

4 Institute for Work \& Health, Toronto, Canada.

5 Workplace/Workforce Theme, HEALNet Network Centre for Excellence, Toronto, Canada.

6 Public Health Sciences, University of Toronto Faculty of Medicine, Toronto, Canada.

7 Manitoba Centre for Health Policy and Evaluation, University of Manitoba, Winnipeg, Canada.

Reprint requests to: Dr Allen Kraut, Department of Community Health Sciences, University of Manitoba, S112-750 Bannatyne Avenue, Winnipeg, Manitoba, R3E 0W3. [E-mail: akraut@ms.umanitoba.ca] 
unhealthy workers into unemployment has been constrained by the relative absence of information on health status prior to the incidence of unemployment.

Theoretically, factory closure studies are ideally suited to provide useful information on the direction of the association of unemployment and poor health as they identify a group of people who lose their job irrespective of their underlying health status and can be followed prospectively $(17,18)$. However this design may not address the relationship between health and unemployment in the general population, where many persons have lost their jobs for other causes. A review of factory closure studies found that only 2 of 10 studies had a study population of over 130, and only 4 had an adequate reference population (19).

Few studies have had the ability to analyze information prior to a large number of persons becoming unemployed and simultaneously control for potential confounding variables at the individual level. Lahelma (20), using spells of unemployment and reemployment, has shown the impact of unemployment on mental health. While the work of Moser et al (1) suggests an effect on physical health. The relationship between unemployment a. 1 adverse health outcomes is influenced by the level of unemployment (10). Higher observed effects at lower unemployment rates are consistent with selection. Support for both competing hypotheses can be found in the literature as the 2 are not mutually exclusive.

This prospective study reports on the relationship between unemployment and the use of health care services for a representative sample in one Canadian province.

\begin{tabular}{|c|c|c|}
\hline \multicolumn{3}{|c|}{ Members of linked dataset, $N=44629$} \\
\hline \multicolumn{3}{|c|}{ Not in labor force, $N=23146$} \\
\hline \multicolumn{3}{|c|}{ Labor force participants, $N=21483$} \\
\hline \multicolumn{3}{|c|}{$\begin{array}{l}\text { Not covered by MHSIP due to } 1983-1989 \\
\text { migration, } N=1557\end{array}$} \\
\hline \multicolumn{3}{|c|}{ Covered by MHSIP through study period, $N=19926$} \\
\hline \multicolumn{3}{|c|}{ Never employed, $N=156$} \\
\hline \multicolumn{3}{|c|}{ Employed and unemployed, $N=19770$} \\
\hline \multicolumn{3}{|c|}{ Employed at time of census, $N=18272$} \\
\hline \multicolumn{3}{|c|}{ Unemployed at time of census, $N=1498$} \\
\hline \multicolumn{3}{|c|}{$x=2+2=-2+\ldots+\ldots$} \\
\hline $\begin{array}{l}\text { Unemployed in } \\
1986, N=690\end{array}$ & $\begin{array}{l}\text { Unemployed in } \\
1985, N=548\end{array}$ & $\begin{array}{l}\text { Unemployed } \\
\text { before 1985, } \\
N=260\end{array}$ \\
\hline
\end{tabular}

Figure 1. Description of the study population. (MHSIP = Manitoba Health Services Insurance Plan)
The study was designed to test 2 hypotheses, first, that persons who become unemployed are a random selection of the labor force with respect to measures of health care use prior to unemployment and, second, that the acute effects of unemployment would result in higher use of health care services during spells of unemployment.

\section{Subjects and methods}

\section{Study population, study design and sources of data}

The study population was a sample of labor force participants in the province of Manitoba. The study design combined comprehensive longitudinal histories of health care utilization over a 7-year period from 1983 to 1989 with cross-sectional information on labor market experiences in the period 1985-1986 for a sample of 19770 persons between 15 and 64 years of age. Information on health care utilization was obtained from administrative records of physician services and hospital care maintained by the Manitoba Health Services Insurance Plan (MHSIP), the single-payer health care insurance agency in this setting. Information on labor market experiences, occupation, and other socioeconomic attributes of the study sample was obtained from responses provided to the 1986 federal census.

\section{Study sample}

The study sample of labor force participants was drawn from a research data base composed of a $5 \%$ sample of the 1050000 residents of Manitoba, Canada, selected by stratified sampling from respondents to the federal 1986 census. For each sampled respondent, information on demographic and socioeconomic characteristics was linked to records of health care utilization, migration, and vital status for a 7-year period from 1983 to 1989 . The method used to link the census records to health care utilization records has been described previously $(21-25)$.

A total of 21483 labor force participants were eligible for inclusion in the study. Persons not continuously resident in the province over the 7-year observation period $(\mathrm{N}=1557)$ or who reported never working $(\mathrm{N}=156)$ were excluded from this sample, leaving a total of 19770 persons. The population estimates produced from the sample accurately reflected the sociodemographic profile, mortality experience, and health care utilization of Manitoba residents (21). Figure 1 describes the study sample.

\section{Measures}

Outcome measure. Electronic records of inpatient hospital admissions and ambulatory physician contacts were the source of the study outcome measures. These records 
contained unique numeric personal identifiers which can be used to create longitudinal person-based histories of health care utilization (26). Hospital separation abstracts record up to 16 diagnoses defining patient health status, and physician reimbursement claims record the single diagnosis most responsible for the patient encounter. Diagnoses are recorded in the ICD-9-CM standard (27). This diagnostic information was used to group healthservice use into 3 categories identifying the treatment of mental health disorders (ICD 290-319), injury and poisoning (ICD 800-999), and cardiovascular disorders (ICD 390-459). Health services associated with pregnancy, labor, and delivery (ICD 630-676) were excluded.

Employment status. Standard Statistics Canada definitions were used to determine the employment status of the labor force participants in June 1986. Among the unemployed workers, the initiation date of the current unemployment spell was not recorded by the census questionnaire. Approximate information on duration of unemployment was obtained from a question that asked if the unemployed person last worked in 1986, during 1985, or prior to 1985 . No information was available on labor force participation and employment status in the 3.5-year observation period following the census. Similarly, no retrospective information on employment status over the period 1983 to June 1986 was available for persons employed on the census day.

For unemployed persons, health care use was classified into 4 observation periods: (i) before the current spell of unemployment, (ii) a transitional period during which a person moved from being employed to being unemployed, (iii) the period of unemployment, and (iv) the 36 month period following December 1986 . For persons reporting unemployment status in June 1986, the remainder of the 1986 calendar year was classified into the "during unemployment" period. Because the specific date in the transitional period when the person became unemployed was not measured by the census, this period contained time prior to the person becoming unemployed and the time during a period of unemployment. Since concern about job loss may have adverse health effects (2830 ) and the earliest period of unemployment may have acute effects on health and on health care behavior, we separated this period from the "during unemployment" period. Table 1 describes the temporal organization of health care use for the unemployed in relation to duration of unemployment.

In our sample, 1498 persons were unemployed on the census day (weighted estimate $6.3 \%$ of the labor force), agreeing closely with the official unemployment estimate at the time of the census (6.5\%) (31). During the 1980s, the monthly unadjusted unemployment rates in Manitoba ranged from a low of $4.6 \%$ in June 1980 to a high of $11.1 \%$ in January 1983 (31). The average monthly unemployment rate was approximately $7.7 \%$. Unemployment rates are lower in Manitoba in the summer months.

Demographic and socioeconomic characteristics. Measures of age, gender, marital status, Aboriginal heritage (race), attained education, sources and amounts of personal and household income, self-reported occupation, and region of residence were obtained from responses to the June 1986 census (table 2).

Mental health status prior to unemployment. Because mental health disorders have negative impacts on labor force participation $(32,33)$, the complete labor force sample was stratified on the basis of a history of treatment for mental health conditions prior to the June 1986 census date. A history of treatment for a mental health disorder was defined as $\geq 1$ hospital admissions or $\geq 2$ physician contacts for the treatment of mental health conditions (ICD 290-319). When this definition was applied, 1208 respondents $(6.1 \%)$ had a history of mental health care use.

\section{Analytic method}

Crude rates of hospital admission and physician service use (1000 person-years) are reported, weighted by respondent sample weights, comparing employed with unemployed cohort members. For the unemployed, rates of health care use were stratified into the 4 observation periods. Ratios of adjusted rates of health care utilization (and 95\% confidence intervals) were computed to compare the unemployed with the employed reference group, as adjusted for age, gender, education, race, area of residence, calendar year, and household income. Measures of hospital use and physician service use were analyzed under assumptions of a Poisson distribution, using the GENMOD procedure in the Statistical Analysis System

Table 1. Classification of health care use by period of unemployment.

\begin{tabular}{|c|c|c|c|c|c|c|c|}
\hline $\begin{array}{l}\text { Date of initiation } \\
\text { of unemployment }\end{array}$ & $N$ & 1983 & 1984 & 1985 & $\begin{array}{c}\text { January } 1 \text { - } \\
\text { June } 3 \\
1986\end{array}$ & $\begin{array}{c}\text { June } 4 \text { - } \\
\text { December } 31 \\
1986\end{array}$ & $1987-1989$ \\
\hline Prior to 1985 & 260 & Before & Transitional & During & During & During & Follow up \\
\hline $\ln 1985$ & 548 & Before & Before & Transitional & During & During & Follow up \\
\hline In 1986 & 690 & Before & Before & Before & Transitional & During & Follow up \\
\hline
\end{tabular}


Table 2. Demographic characteristics of the labor force participants, Manitoba, Canada, 1986.

\begin{tabular}{|c|c|c|c|c|c|c|c|c|c|c|c|c|c|}
\hline \multirow[t]{2}{*}{ Employment status } & \multirow{2}{*}{$\begin{array}{c}\text { Un- } \\
\text { weighted } \\
\text { (N) }\end{array}$} & \multirow{2}{*}{$\begin{array}{l}\text { Weight- } \\
\text { ed } \\
(\mathrm{N})^{\mathrm{a}}\end{array}$} & \multirow{2}{*}{$\begin{array}{c}\text { Mean } \\
\text { age } \\
\text { (years) }\end{array}$} & \multirow[t]{2}{*}{$\begin{array}{l}\text { Male } \\
(\%)\end{array}$} & \multicolumn{3}{|c|}{$\begin{array}{l}\text { Residence } \\
(\%)\end{array}$} & \multicolumn{3}{|c|}{$\begin{array}{l}\text { Education } \\
\qquad \%)\end{array}$} & \multirow[t]{2}{*}{$\begin{array}{c}\text { Married } \\
(\%)\end{array}$} & \multirow{2}{*}{$\begin{array}{l}\text { Abo- } \\
\text { riginal } \\
\text { race } \\
(\%)\end{array}$} & \multirow{2}{*}{$\begin{array}{l}\text { House- } \\
\text { hold } \\
\text { income } \\
\text { (CAD) }\end{array}$} \\
\hline & & & & & $\begin{array}{l}\text { Winni- } \\
\text { peg }\end{array}$ & $\begin{array}{c}\text { Urban } \\
\text { non- } \\
\text { Winni- } \\
\text { peg }\end{array}$ & Rural & $\begin{array}{l}\text { Grade } \\
0-9\end{array}$ & $\begin{array}{c}\text { Grade } \\
10-12\end{array}$ & $\begin{array}{l}\text { Some } \\
\text { univer- } \\
\text { sity } \\
\text { or post- } \\
\text { second- } \\
\text { ary }\end{array}$ & & & \\
\hline $\begin{array}{l}\text { Employed } \\
\text { Unemployed }\end{array}$ & 18272 & 18518.0 & 38.0 & 57.6 & 58.3 & 14.9 & 26.8 & 17.1 & 36.1 & 46.9 & 67.5 & 1.5 & 40500 \\
\hline $\begin{array}{l}\text { Current episode } \\
\text { initiated in } 1986\end{array}$ & 690 & 623.9 & 33.2 & 51.4 & 62.3 & 14.6 & 23.1 & 21.0 & 39.1 & 39.8 & 51.4 & 5.7 & 35300 \\
\hline $\begin{array}{l}\text { Current episode } \\
\text { initiated in } 1985\end{array}$ & 548 & 435.6 & 32.5 & 53.7 & 60.6 & 11.0 & 28.4 & 20.9 & 43.5 & 35.6 & 49.0 & 11.1 & 34200 \\
\hline $\begin{array}{l}\text { Current episode } \\
\text { initiated before } 1985\end{array}$ & 260 & 192.3 & 36.2 & 48.0 & 57.1 & 13.1 & 29.8 & 24.9 & 38.9 & 36.2 & 49.6 & 18.8 & 20500 \\
\hline
\end{tabular}

a All the values were derived from weighted sample estimates.

Table 3. Comparison of all causes of health care utilization between the employed and unemployed labor force participants, Manitoba,

\begin{tabular}{|c|c|c|c|c|c|c|c|}
\hline & \multicolumn{3}{|c|}{ Employed } & & & & \\
\hline & \multirow[t]{2}{*}{$N^{c}$} & \multirow[t]{2}{*}{ Rate $^{d}$} & \multirow[t]{2}{*}{$\mathrm{RR}^{\mathrm{e}}$} & \multicolumn{4}{|c|}{ Before } \\
\hline & & & & $N^{c}$ & Rate $^{d}$ & $\mathrm{RR}^{\mathrm{e}}$ & $95 \% \mathrm{Cl}$ \\
\hline \multicolumn{8}{|l|}{ Hospitalization } \\
\hline Entire cohort & 9502 & 72.0 & 1.0 & 301 & 89.8 & 1.34 & $1.12-1.60$ \\
\hline Cohort members with history of mental health care & 1289 & 151.8 & 1.0 & 77 & 331.9 & 2.09 & $1.46-2.99$ \\
\hline Cohort members with no history of mental health care & 8213 & 66.1 & 1.0 & 224 & 68.2 & 1.15 & $0.95-1.39$ \\
\hline \multicolumn{8}{|l|}{ Ambulatory care } \\
\hline Entire cohort & 485964 & 4.0 & 1.0 & 11395 & 4.1 & 1.07 & $1.00-1.15$ \\
\hline Cohort members with history of mental health care & 74252 & 9.2 & 1.0 & 2080 & 10.2 & 1.04 & $0.83-1.29$ \\
\hline Cohort members with no history of mental health care & 411712 & 3.6 & 1.0 & 9315 & 3.5 & 1.06 & $0.99-1.13$ \\
\hline
\end{tabular}

a Indicates the results that were significantly different from the before period when that period was used as the reference.

c Number of hospitalizations or ambulatory care contacts.

e Adjusted for age, gender, education, race, area of residence, calendar year, and household income.

Table 4. Comparison of hospital admission rates and ambulatory care contact rates for the treatment of mental health conditions and $95 \% \mathrm{Cl}=95 \%$ confidence interval)

\begin{tabular}{|c|c|c|c|c|c|c|c|}
\hline & \multicolumn{3}{|c|}{ Employed } & & & & \\
\hline & \multirow[t]{2}{*}{$\mathrm{N}^{\mathrm{c}}$} & \multirow[t]{2}{*}{ Rated } & \multirow[t]{2}{*}{$\mathrm{RR}^{\mathrm{e}}$} & \multicolumn{4}{|c|}{ Before } \\
\hline & & & & $N^{c}$ & Rate $^{d}$ & $\mathrm{RR}^{\mathrm{e}}$ & $95 \% \mathrm{Cl}$ \\
\hline \multicolumn{8}{|l|}{ Mental health conditions } \\
\hline Entire cohort hospitalization & 420 & 3.2 & 1.0 & 32 & 11.2 & 3.60 & $2.11-6.14$ \\
\hline Entire cohort abulatory contacts & 34201 & 296 & 1.0 & 788 & 313 & 1.37 & $0.96-1.95$ \\
\hline $\begin{array}{l}\text { Hospital admissions for cohort members with } \\
\text { no history of mental health care }\end{array}$ & 126 & 1.8 & 1.0 & & & & \\
\hline $\begin{array}{l}\text { Ambulatory contacts for cohort members with } \\
\text { no history of mental health care }\end{array}$ & 11015 & 168 & 1.0 & . & & . & . \\
\hline \multicolumn{8}{|l|}{ Injuries and poisonings } \\
\hline $\begin{array}{l}\text { Entire cohort Hospitalization } \\
\text { Entire cohort }\end{array}$ & 1052 & 7.4 & 1.0 & 55 & 14.9 & 1.49 & $1.02-2.18$ \\
\hline Ambulatory contacts & 48563 & 392 & 1.0 & 1379 & 458 & 1.03 & $0.91-1.16$ \\
\hline $\begin{array}{l}\text { Hospital admissions for cohort members with } \\
\text { no history of mental health care }\end{array}$ & 942 & 7.0 & 1.0 & 46 & 13.2 & 1.38 & $0.90-2.11$ \\
\hline $\begin{array}{l}\text { Ambulatory contacts for cohort members with } \\
\text { no history of mental health care }\end{array}$ & 43853 & 379 & 1.0 & 1215 & 428 & 1.00 & $0.87-1.14$ \\
\hline
\end{tabular}

a Indicates the results that were significantly different from the before period when that period was used as the reference.

- Number of events.

\& Adjusted for age, gender, education, race, area of residence, calendar year, and household income. 
(SAS) to account for the correlated structure of the repeated contacts for health care use for each person over the 7-year period. The use of the repeated measures (eg, the average of 4 ambulatory contacts per person per year) explained the very high number of contacts identified for the analysis. Interaction terms were included where indicated. Normalized sample weights were incorporated into the analyses to adjust the effect size estimates arising from the stratified sample design. Because previous work had established that the sampling design had weak effects on the variance estimates, analytic tools to adjust the variance estimates were not used.

These multivariate analyses were repeated after the sample had been stratified by status as to mental health treatment. Analyses were also conducted for the 3 subsidiary groupings of health care use: mental health disorders, injuries and poisonings, and cardiovascular disorders. Also included in the reported results are statistical tests for differences in health care utilization for the unemployed group using the before period as a reference for the other observation periods.

Finally, a logistic regression model was used to test for a relationship between prior health care use and the subsequent risk of becoming unemployed.

\section{Results}

Comparisons of hospital and ambulatory care utilization are shown in table 3. The unemployed had significantly higher rates of hospital admissions than the employed group in all 4 observation periods, the adjusted relative

Canada, $1983-1989 .{ }^{a}(\mathrm{RR}=$ rate ratio, $95 \% \mathrm{Cl}=95 \%$ confidence interval)

\begin{tabular}{|c|c|c|c|c|c|c|c|c|c|c|c|}
\hline \multicolumn{12}{|c|}{ Unemployed ${ }^{\mathrm{b}}$} \\
\hline \multicolumn{4}{|c|}{ Transitional } & \multicolumn{4}{|c|}{ During } & \multicolumn{4}{|c|}{ Follow-up } \\
\hline No & Rated & $\mathrm{RR}^{\mathrm{e}}$ & $95 \% \mathrm{Cl}$ & $N^{c}$ & Rated & $\mathrm{RR}^{\mathrm{e}}$ & $95 \% \mathrm{Cl}$ & $\mathrm{N}^{\mathrm{e}}$ & Rate $^{d}$ & $\mathrm{RR}^{\mathrm{\theta}}$ & $95 \% \mathrm{Cl}$ \\
\hline 138 & 102.3 & 1.45 & $1.14-1.86$ & 158 & 93.6 & 1.32 & $1.05-1.66$ & 525 & 96.6 & 1.33 & $1.13-1.56$ \\
\hline 17 & 212.4 & 1.24 & $0.57-2.69$ & 16 & 169.4 & 1.16 & $0.57-2.36$ & 28 & 84.6 & $0.71 \mathrm{a}$ & $0.39-1.27$ \\
\hline 121 & 93.1 & 1.49 & $1.15-1.92$ & 142 & 87.2 & 1.36 & $1.07-1.72$ & 497 & 97.7 & $1.43^{a}$ & $1.21-1.68$ \\
\hline 4351 & 4.4 & 1.07 & $0.99-1.16$ & 6247 & 4.6 & 1.13 & $1.05-1.22$ & 20717 & 4.8 & 1.13 & $1.06-1.20$ \\
\hline 682 & 10.7 & 0.98 & $0.73-1.30$ & 875 & 10.2 & 0.94 & $0.73-1.23$ & 2637 & 9.2 & 1.02 & $0.82-1.27$ \\
\hline 3669 & 3.8 & 1.09 & $1.01-1.17$ & 5372 & 4.2 & 1.15 & $1.06-1.24$ & 18080 & 4.4 & 1.14 & $1.07-1.22$ \\
\hline
\end{tabular}

Before, transitional, during, and follow-up refer to the sequential time periods related to the onset of the current period of unemployment

¿ Weighted rates per 1000 person-years for hospitalization and per person-year for ambulatory care contacts.

injuries and poisonings between the employed and unemployed labor force participants, Manitoba, Canada, 1983-1989.a (RR= rate ratio,

\begin{tabular}{|c|c|c|c|c|c|c|c|c|c|c|c|}
\hline \multicolumn{12}{|c|}{ Unemployed ${ }^{\mathrm{b}}$} \\
\hline \multicolumn{4}{|c|}{ Transitional } & \multicolumn{4}{|c|}{ During } & \multicolumn{4}{|c|}{ Follow-up } \\
\hline$N^{c}$ & Rated & $\mathrm{RR}^{\mathrm{e}}$ & $95 \% \mathrm{Cl}$ & $N^{c}$ & Rated $^{d}$ & $\mathrm{RR}^{\mathrm{e}}$ & $95 \% \mathrm{Cl}$ & $N^{c}$ & Rate $^{d}$ & $R^{0}$ & $95 \% \mathrm{Cl}$ \\
\hline $\begin{array}{r}17 \\
430\end{array}$ & $\begin{array}{l}17.1 \\
496\end{array}$ & $\begin{array}{l}4.70 \\
1.40\end{array}$ & $\begin{array}{l}2.21-9.99 \\
0.94-2.07\end{array}$ & $\begin{array}{r}10 \\
620\end{array}$ & $\begin{array}{r}7.4 \\
534\end{array}$ & $\begin{array}{l}1.77 \\
1.61\end{array}$ & $\begin{array}{l}0.72-4.35 \\
1.13-2.30\end{array}$ & $\begin{array}{r}27 \\
1812\end{array}$ & $\begin{array}{r}5.4 \\
468\end{array}$ & $\begin{array}{l}1.21 \\
1.44\end{array}$ & $\begin{array}{c}0.64-2.30^{\circ} \\
1.08-1.93\end{array}$ \\
\hline 8 & 6.8 & 6.15 & $1.50-25.29$ & 6 & 3.9 & 2.79 & $0.67-11.74$ & 18 & 3.1 & 1.34 & $0.64-2.84$ \\
\hline 166 & 170 & 1.42 & $0.98-2.05$ & 311 & 266 & 1.87 & $1.25-2.80$ & 1102 & 295 & 1.70 & $1.21-2.41$ \\
\hline 32 & 18.3 & 1.87 & $1.13-3.09$ & 40 & 18.6 & 2.02 & $1.27-3.21$ & 101 & 15.8 & 2.00 & $1.47-2.73$ \\
\hline 532 & 506 & 1.08 & $0.93-1.26$ & 730 & 490 & 1.18 & $0.99-1.41$ & 2360 & 468 & 1.13 & $1.03-1.25$ \\
\hline 32 & 19.8 & 2.15 & $1.30-3.66$ & 38 & 18.1 & 2.10 & $1.29-3.40$ & 98 & 16.5 & 2.25 & $1.64-3.09$ \\
\hline 495 & 470 & 1.13 & $0.96-1.33$ & 681 & 502 & 1.22 & $1.01-1.47^{\mathrm{a}}$ & 2188 & 482 & 1.15 & $1.04-1.28$ \\
\hline
\end{tabular}

Before, transitional, during, and follow-up refer to the sequential time periods related to the onset of the current period of unemployment.

Weighted rates per 1000 person-years. 
rate ratios ranging from 1.34 in the period before the current spell of employment to 1.33 in the follow-up period. Rates of ambulatory care use were also higher for the unemployed relative to the employed in all 4 observation periods.

Table 3 also reports results stratified by history of treatment for a mental health disorder. For those with no history of mental health treatment, the rates of hospital admission and ambulatory care were equivalent between the employed and unemployed groups prior to the current episode of unemployment. In the 3 subsequent periods, however, the rates of both hospital admission and ambulatory care for all disorders combined were significantly elevated in the unemployed group.

Among both the employed and unemployed with a history of treatment for a mental health disorder, the rates of health care utilization for all disorders combined were consistently 2 to 3 times higher than those without a history of mental health treatment. In the group with a history of mental health treatment, there was no observed difference in the use of ambulatory care between the unemployed and employed groups in any of the 4 observation periods. The unemployed had a significantly higher use of hospital care relative to that of the employed in the before period [adjusted rate ratio (RR) $2.09,95 \%$ confidence interval (95\% CI) 1.46-2.99]. The hospitalization rate ratio declined over the subsequent periods.

The all-cause hospitalization rates were significantly lower in the follow-up period when compared with the before period for those with a history of prior mental health care. The opposite was true for those without such a history.

The rates of hospital admission for the treatment of mental health disorders were elevated in the unemployed group relative to those of the employed group in the before and transitional periods (table 4, see p 172-173). The rates of ambulatory care for the treatment of mental health disorders in the unemployed group were elevated in the period during the episode of unemployment and also during the follow-up period. For both hospital

Table 5. Risk of unemployment in relation to prior health care use, by period of onset of unemployment, Manitoba labor force participants, $1986 .(95 \% \mathrm{Cl}=95 \%$ confidence interval, NS = not significant at 0.05 level, .. = not entered $)$

\begin{tabular}{|c|c|c|c|c|c|c|}
\hline \multirow[t]{3}{*}{ Covariate } & \multicolumn{6}{|c|}{ Onset of current unemployment episode } \\
\hline & \multicolumn{2}{|c|}{1986} & \multicolumn{2}{|c|}{1985} & \multicolumn{2}{|c|}{ Before 1985} \\
\hline & Risk & $95 \% \mathrm{Cl}$ & Risk & $95 \% \mathrm{Cl}$ & Risk & $95 \% \mathrm{Cl}$ \\
\hline \multicolumn{7}{|l|}{ Nonhealth-care-related variables } \\
\hline Age & 0.98 & $0.97-0.98$ & 0.98 & $0.97-0.98$ & NS & \\
\hline Age squared & 1.00 & $1.00-1.00$ & 1.00 & $1.00-1.00$ & NS & . \\
\hline Malea & 1.28 & $1.01-1.64$ & 1.36 & $1.02-1.82$ & 1.29 & $0.85-1.95$ \\
\hline Marrieda & 1.22 & $0.95-1.57$ & 1.23 & $0.90-1.69$ & 0.87 & $0.58-1.30$ \\
\hline Male $\times$ married & 0.37 & $0.27-0.52$ & 0.32 & $0.21-0.47$ & 0.31 & $0.17-0.55$ \\
\hline Aboriginal & 2.12 & $1.10-4.10$ & 3.48 & $1.79-6.77$ & 15.14 & $10.29-22.26$ \\
\hline Male $\times$ aboriginal & 2.53 & $1.14-5.58$ & 3.32 & $1.54-7.17$ & NS & . \\
\hline Winnipeg (reference rural) & 1.31 & $1.10-1.56$ & 1.35 & $1.10-1.66$ & NS & . \\
\hline Grade $10-12($ reference $<$ grade 10$)$ & 0.63 & $0.50-0.80$ & 0.73 & $0.55-0.97$ & NS & 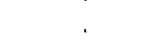 \\
\hline Some postsecondary (reference < grade 10) & 0.56 & $0.44-0.71$ & 0.52 & $0.39-0.70$ & NS & , \\
\hline \multicolumn{7}{|l|}{ Health care utilization variables } \\
\hline \multicolumn{7}{|l|}{ Mental health ${ }^{\circ}$} \\
\hline Hospitalization in 1983 & NS & . & 3.17 & $1.12-8.98$ & NS & . \\
\hline Hospitalization in 1984 & NS & . & 5.51 & $2.34-12.97$ & .. & . \\
\hline Hospitalization in 1985 & NS & . & .. & . & .. & . \\
\hline Hospitalization in 1986 (precensus) & .. & . & .. & . & .. & . \\
\hline Ambulatory contacts 1983 & NS & . & NS & . & 2.54 & $1.45-4.45$ \\
\hline Ambulatory contacts 1984 & NS & . & NS & . & $\therefore$ & . \\
\hline Ambulatory contacts 1985 & 1.57 & $1.10-2.25$ & .. & . &. & . \\
\hline Ambulatory contacts 1986 (precensus) & .. & . & .. & . &.. & . \\
\hline Nonmental health ${ }^{\varepsilon}$ & & & & & & . \\
\hline Hospitalization in 1983 & NS & . & NS & . & NS & . \\
\hline Hospitalization in 1984 & NS & . & NS & . & .. & . \\
\hline Hospitalization in 1985 & 1.45 & $1.07-1.97$ &.. & . &.. & . \\
\hline Hospitalization in 1986 (precensus) & .. & . & & . & .. & . \\
\hline Ambulatory contacts 1983 & 1.24 & $1.01-1.50$ & NS & . & NS & . \\
\hline Ambulatory contacts 1984 & NS & . & NS & . & .. & . \\
\hline Ambulatory contacts 1985 & NS & . & .. & . &.. & . \\
\hline Ambulatory contacts 1986 (precensus) &.. & . &.. & . &.. & . \\
\hline
\end{tabular}

a Forced in due to significant interaction term.

- Hospitalization refers to $\geq 1$ periods of hospitalization for a mental health diagnosis; ambulatory contacts refer to $\geq 2$ physician encounters for a mental health diagnosis.

" Hospitalization refers to $\geq 1$ periods of hospitalization for a nonmental health diagnosis; ambulatory contacts refer to $\geq 5$ physician contacts for a nonmental health diagnosis. 
admissions and ambulatory care, the results persisted in analyses excluding labor force participants with a prior history of mental health treatment. There were empty cells in the before period in this analysis as the claims definition used to identify persons with mental health conditions eliminated persons who had mental health care contacts prior to their onset of unemployment.

The rates for hospital and ambulatory care utilization for the treatment of injury and poisoning were elevated in the unemployed group during the transitional period, the period of unemployment, and the follow-up period (table 4, see p 172-173), both for the complete labor force sample and after control for prior history of mental health treatment. In the period before the initiation of the current unemployment episode, the rates of ambulatory care use for the treatment of injury did not differ between the unemployed and employed persons. A significant difference in the rate of hospital admission for these conditions in the before period (RR $1.49,95 \%$ CI $1.02-2.18$ ) was not sustained when persons with a history of mental health treatment were excluded from the analysis (RR $1.38,95 \%$ CI $0.9-2.11$ ). There were no consistent differences between the employed and unemployed persons with respect to the rates of hospital admission and ambulatory care for the treatment of cardiovascular disorders.

In table 5, the analytic perspective is reversed. In this table, the relationship between prior health care use and the subsequent risk of unemployment is estimated, stratified into the 3 groups of persons who became unemployed in 1986, those who became unemployed in 1985 , and those who became unemployed prior to 1985. In a consistent finding across all 3 groups, the approximately $6 \%$ of the labor force with a treatment history for mental health conditions had an elevated risk of subsequent unemployment. For each of the subcohorts 1 mental health variable, either hospitalization or ambulatory contacts, in the period immediately prior to the initiation of unemployment predicted unemployment. For example, among the labor force participants employed in 1985 who had $\geq 2$ ambulatory physician contacts for mental health care in this period ( $3.5 \%$ of the employed cohort in 1985), the risk of 1986 unemployment was 1.57 times greater than for those not in treatment in 1985 (95\% CI 1.102.25 ). In contrast, health care utilization for nonmental health disorders prior to unemployment only predicted unemployment for the subcohort that became unemployed in 1986.

\section{Discussion}

This prospective study was designed to test 2 competing explanations for the frequently observed cross-sectional finding that unemployed labor force participants have ev- idence of poorer health status than employed persons do, namely, the causal explanation, where unemployment precipitates declines in health, and the selection explanation, where individuals for socioeconomic, health, or other reasons experience a higher risk of simultaneously becoming unemployed and having worse health outcomes.

To examine these questions, the study has used measures of health care utilization as a proxy for direct measures of health status. Consistent with recent data (7), evidence was found to support both the selection and causation hypotheses. Support for selection was found in comparisons of the entire cohort of labor force participants. Persons who became unemployed were shown not to be a random sample of the labor force according to prior health status. In the unemployed group, the use of both hospital care and ambulatory physician services was elevated relative to that of the employed group in the period prior to the incidence of unemployment. Unemployed persons with prior mental health care had increased hospitalization rates before their current period of unemployment. Other evidence supporting selection was found in the analysis of predictors of unemployment. Prior health care utilization was found to predict subsequent unemployment. Mental health care utilization in the period preceding the onset of unemployment predicted unemployment in all 3 subcohorts of the unemployed. Nonmental health variables only predicted unemployment in the "unemployed in 1986" subcohort (ie, that with the shortest duration of unemployment). Nonmental health utilization may not have predicted unemployment for the groups with longer unemployment, since to be "officially unemployed" one has to be actively seeking work, those who have chronic illnesses may have selected themselves out of the work force (34).

Evidence supporting causation was found when members of the cohort with a history of mental health treatment were excluded from the analysis, the use of hospital care and ambulatory physician services was comparable between the employed and unemployed in the period prior to the incidence of unemployment. In this group health care utilization increased among the unemployed during the periods of transition to unemployment, the period during unemployment, and the follow-up period.

Diagnosis-specific analyses also provided evidence supporting the hypothesis that the experience of unemployment is causally implicated in adverse changes in health status. Among persons with no history of mental health treatment, the incidence of hospital admission for the treatment of injury and poisoning increased among the unemployed during the transitional, unemployment, and follow-up periods. Possible mechanisms for this observation may include increased use of alcohol, which has been observed in some (12), but not all (35), 
situations or mental stress leading to self-abusive behavior (36). In this same unemployed group with no history of mental health treatment, the frequency of hospitalization and ambulatory encounters with physicians for the treatment of mental health disorders were elevated in all 3 observation periods defining the unemployment experience, with the exception of the follow-up period for hospitalization. This finding is also consistent with the results of previous research $(20,37)$ showing negative effects of unemployment on mental health.

Stratification revealed different patterns in the relationship of health care utilization and unemployment for those who had a history of treatment for mental health care and those who did not. Those with mental health diagnoses who remained in the work force had a decrease in hospitalization throughout the study period, while an increase in hospitalization was observed for those without these diagnoses. The observed decrease in hospitalization may be due to a survivor effect, with only those healthy enough to look for work remaining in the labor force. We were unable to identify other work using population-based cohorts stratified according to mental health. This finding is consistent with other research which has found that aggregate reporting of data may obscure specific information (16).

Our study had several limitations. An observed increase in health care utilization may be due to healthcare-seeking behavior and not due to a change in health status. Our results showed greater differences in hospitalization than for ambulatory care utilization and in health care treatment for injuries and poisonings than for other conditions. This pattern is more in keeping with a change in health status of the unemployed rather than an increase in health-care-seeking behavior. Misclassification may also have occurred, as we were not able to identify employment status at times other than at the census. Generally, misclassification tends to obscure associations (38); thus our results may have underestimated the true effect of unemployment on health care utilization. Another potential source of misclassification could occur by using administrative data to identify individuals who had mental health conditions. These data would not identify persons who may be considered by clinical criteria to have mental health conditions. Another limitation is that the group of unemployed persons would not include discouraged workers who left the work force prior to the census or people who were selected out of the work force by poor health status. People who were previously unemployed have a greater chance of again being unemployed, a factor leading to occupational marginization ( 7 , 16). Exclusion of these types of persons would create bias against finding effects of unemployment, as only persons well enough to continue seeking work could be studied. A further limitation is that we were not certain of the exact date when unemployment commenced. This limitation was addressed by comparing utilization in periods before and during a spell of unemployment, the results showing changes consistent with an unemployment effect. The relatively low unemployment rate at the time of the study may have caused some of the observed associations between health care utilization and unemployment (10). Our analysis was designed to identify utilization prior to unemployment to identify better those who may be selected into unemployment and to control for this possibility. Although we were able to control for many potential confounding variables, we were not able to control for others, such as cigarette and alcohol consumption (35) or childhood socioeconomic circumstances (15). Thus we cannot exclude confounding by these or other variables as the cause of the observed increase in health care utilization.

Overall, our data were consistent with a selection effect of persons with a history of mental health care utilization into unemployment. This study is consistent with previous research on labor market experiences that indicate that mental health disorders increase the risk of unemployment $(32,33)$. However, for the majority of the unemployed in this sample, the elevated use of hospital care and ambulatory physician services during the unemployment experience was not explained by a prior history of health care use, and it replicates findings of other studies which have documented increases in the use of health care during unemployment $(2,17,37,39)$. Future research that utilizes population-based data sets should control for prior mental health care, as it may obscure a causal relationship between unemployment and adverse health outcomes.

\section{Acknowledgments}

Funding for this research was provided in part by the National Health Research Development Program, Health Canada. Dr Mustard is a recipient of a Medical Research Council of Canada scientist award.

\section{References}

1. Moser KA, Goldblatt PO, Fox AJ, Jones DR. Unemployment and mortality: comparison of the 1971 and 1981 longitudinal study census samples. BMJ [Clinical Research Edition] 1987;294(6564):86-90.

2. Linn MW, Sandifer R, Stein S. Effects of unemployment of mental and physical health. Am J Public Health 1985; 75(5):502-6.

3. Martikainen PT. Unemployment and mortality among Finnish men, 1981-5. BMJ 1990;301:407-11.

4. Morris JK, Cook DG, Shaper AG. Loss of employment and 
mortality. BMJ 1994;308:1135-9.

5. D'Arcy C, Siddique CM. Unemployment and health: an analysis of "Canada Health Survey" data Int J Health Serv 1985;15(4):609-35. [Published erratum appears in Int J Health Serv 1987;17(2):368].

6. Jin RL, Shah CP, Svoboda TJ. The impact of unemployment on health: a review of the evidence. Can Med Assoc J 1995;153(5):529—40.

7. Liira J, Leino-Arjas P. Predictors and consequences of unemployment in construction and forest work during a 5-year follow-up. Scand J Work Environ Health 1999;25:42-9.

8. Valkonen T, Martikainen P. The association between unemployment and mortality: causation or selection? In Lopez AD Caselli G, Valkonen T, editors. Adult mortality in developed countries: from description to explanation. Oxford: Clarendon Press, 1995;201-22.

9. Moser KA, Fox AJ, Jones DR. Unemployment and mortality in the OPCS longitudinal study. Lancet 1984;2:1324-28.

10. Martikainen PT, Valkonen T. Excess mortality of unemployed men and women during a period of rapidly increasing unemployment. Lancet 1996;348:909-12.

11. Lynch JW, Kaplan GA, Shema SJ. Cumulative impact of sustained economic hardship on physical, cognitive, psychological, and social functioning. N Engl J Med 1997; $337: 1889-95$.

12. Janlert U, Hammarström A. Alcohol consumption among unemployed youths: results from a prospective study. $\mathrm{Br} \mathbf{J} \mathrm{Ad}$ dict 1992;87:703:14.

13. Turner JB. Economic context and the health effects of unemployment. J Health Soc Behav 1995;36:213 - 29.

14. Frese M, Mohr G. Prolonged unemployment and depression in older workers: a longitudinal study of intervening variables. Soc Sci Med 1987;25:173-8.

15. Montgomery SM, Bartley MJ, Cook DG, Wadsworth ME. Health and social precursors of unemployment in young men in Great Britain. J Epidemiol Community Health 1996; $50(4): 415-22$.

16. Arrow J. Estimating the influence of health as a risk factor on unemployment: a survival analysis of employment durations for workers surveyed in the German socio-economic panel (1984-1990). Soc Sci Med 1996;42:1651-59.

17. Iversen L, Sabroe S, Damsgaard MT. Hospital admissions before and after shipyard closure. BMJ 1989; 299(6707):1073-6.

18. Westin $\mathrm{S}$. The structure of a factory closure: Individual responses to job-loss and unemployment in a 10-year controlled follow-up study. Soc Sci Med 1990;31:1301-11.

19. Morris JK, Cook DG. A critical review of the effect of factory closures on health. Br J Ind Med 1991;48:1-8.

20. Lahelma E. Unemployment and mental well-being: Elaboration of the relationship. Int J Health Serv 1992;22:261-74.

21. Houle C, Berthelot JM, David P, Mustard CA, Roos LL, Wolfson MC. Project on matching census 1986 database and Manitoba health care files: private households component. Ottawa: Analytic Studies Branch, Statistics, 1996. Research papers series no 91.

22. David P, Berthelot JM, Mustard C. Linking survey and ad- ministrative data to study the determinants of health. Ottawa: Social and Economic Studies Division, Statistics Canada, 1992.

23. Mustard CA, Derksen S, Berthelot JM, Wolfson M, Roos LL Age-specific education and income gradients in morbidity and mortality in a Canadian province. Soc Sci Med 1997;45:383-97.

24. Roos LL, Wajda A. Record linkage strategies part I: estimating information and evaluation approaches. Methods Inf Med 1991;30:117-23.

25. Newcombe HB, Kennedy JM, Axford SJ, James A. Automatic linkage of vital records. Science 1959;130:954-9.

26. Roos LL, Mustard CA, Nicol P, McLerran DF, Malenka DJ, Young TK, et al. Registries and administrative data: organization and accuracy. Med Care 1993;31:201-12.

27. International classification of disease, 9th revision, clinical modification. Ann Arbor (MI): Commission on Professional and Hospital Activities, 1986.

28. Heaney CA, Israel BA, House JS. Chronic job insecurity among automobile workers: effects on job satisfaction and health. Soc Sci Med 1994;38(10):1431-7.

29. Ferrie JE, Shipley MJ, Marmot MG, Stansfeld S, Smith GD. Health effects of anticipation of job change and non-employment: longitudinal data from the Whitehall II study. BMJ 1995;311(7015):1264-9

30. Ferrie JE, Shipley MJ, Marmot MG, Stansfeld S, Smith GD. An uncertain future: the health effects of threats to employment security in white-collar men and women. Am J Public Health 1998;88:1030-6.

31. Statistics Canada. Historical Labour Force Statistics. Catalogue no 71-201-xpb. Ottawa: Statistics Canada, 1997.

32. Dohrenwend BP, Levav I, Shout PE, Schwartz S, Naveh G, Link BG, et al. Socioeconomic status and psychiatric disorders: the causation-selection issue. Science 1992;255;94652.

33. Claussen B, Bjorndal A, Hjort PF. Health and re-employment in a two year follow up of the long term unemployed. J Epidemiol Community Health 1993;47:14-18.

34. Bartley M, Owen C. Relation between socioeconomic status, employment, and health during economic change, 1973-93. BMJ 1996;313:445-9.

35. Morris JK, Cook DG, Shaper AG. Non-employment and changes in smoking, drinking, and body weight. BMJ 1992;304:536-41.

36. Lewis G, Sloggett A. Suicide, deprivation, and unemployment: record linkage study. BMJ 1998;317:1283-6.

37. Platt $S$, Kreitman N. Long term trends in parasuicide and unemployment in Edinburgh, 1968-87. Soc Psychiatry Psychiatr Epidemiol 1990;25:56-61.

38. Armstrong B. Effects of measurement error on epidemiological studies of environmental and occupational exposures. Occup Environ Med 1998;55:651—6.

39. Beale $N$, Nethercott $S$. The nature of unemployment morbidity: 2. description. JR Coll Gen Pract 1988;38:200—2.

Received for publication: 22 March 1999 